\title{
THE HEART LUNG COEFFICIENT IN OLDER PEOPLE
}

\author{
BY \\ NAIRN R. COWAN \\ From the Consultative Health Centre for Older People, Rutherglen, Lanarkshire \\ Received August 28, 1958
}

This study of the heart lung coefficient (Kerley, 1950), which is also known as the heart-lung quotient (White, 1945) and the cardiothoracic ratio (Danzer, 1919), is based on 242 men and 190 women, aged 60 to 89 years. They were examined at the Rutherglen Consultative Health Centre for older people (Anderson and Cowan, 1955) and all were considered to be in good health. In particular, we excluded those who had a hæmoglobin under $11 \mathrm{~g}$. Sahli, varicose veins, an apical systolic murmur greater than Grade 2 as described by Levine and Harvey (1949), an asymmetrical chest, and those who were 25 per cent or more over ideal weight as estimated from Anderson's nomogram (1948).

The heart lung coefficient is the maximum transverse diameter of the heart divided by the maximum transverse diameter of the chest. The measurements were assessed to the nearest millimetre from X-ray films taken in the postero-anterior position at a distance of two metres with an exposure of $1 / 25$ second at 300 milliampres. In all the films the cardiac borders were clearly defined.

The standard procedure for estimating the transverse diameter of the heart is to sum the greatest deviations from the mid-line on the right and left sides. In practice this is a somewhat complicated technique with the further disadvantage that the summation of two measurements is less accurate than one. A simplified method of estimating the maximum transverse diameter of the heart, evolved by the author and Dr. P. L. McKinlay of the Department of Health for Scotland, is used in the present study and is carried out as follows. One edge of the right angle of a large transparent set-square is applied to the mid-vertical line on the X-ray film, and along the other edge a transparent two foot ruler is placed horizontally. The set-square is moved along the ruler's upper border until the vertical margin of the set-square is in line with the outermost part of the right border of the heart. The set-square is held firmly in this position and the ruler moved until the $10 \mathrm{~cm}$. mark is in line with the vertical edge of the set-square. The ruler is now held in place and the set-square slid to the right until its vertical edge coincides with the outermost part of the left border of the heart. The figure on the ruler immediately below the vertical edge of the set-square less $10 \mathrm{~cm}$. is the maximum transverse diameter of the heart.

There is divergence of opinion as to what constitutes the maximum transverse diameter of the chest. Danzer (1919) simply takes the greatest diameter of the chest; Ungerleider and Gubner (1942) merely suggest the transverse diameter at the level of the diaphragm, while Tirman and Hamilton (1952) are precise and measure from the internal surfaces of the ribs on the right and left sides, superior to the costal attachment of the diaphragm at that point where the width of the chest is greatest. The criterion of Tirman and Hamilton is used in this paper.

\section{RESULTS}

The frequency distributions of the 242 men and the 190 women by sex and 10-year age groups with reference to the heart lung coefficient are shown in Table I. There is an upward trend of the distributions with age and for both sexes. Table II shows that the heart lung coefficient means for men increase with age from 0.44 for the age group 60-69 to 0.47 for the age group 80-89, and that the corresponding means for women are 0.50 and 0.54 . Thus the means for women are greater than those for men at all ages. The absolute variation, of which the standard deviation is a measure, is similar for the sexes and shows a slight increase with age. The relative variability, as shown by the coefficient of variation, is similar for the sexes and shows a slight increase with age for women. 
TABLE I

The number of Cases by Sex and 10-year Age Groups with Reference to the Heart Lung Coefficient

\begin{tabular}{|c|c|c|c|c|c|c|}
\hline \multirow{2}{*}{$\begin{array}{l}\text { Heart lung } \\
\text { coefficient }\end{array}$} & \multicolumn{3}{|c|}{ Men } & \multicolumn{3}{|c|}{ Women } \\
\hline & $\begin{array}{l}60-69 \\
\text { years }\end{array}$ & \begin{tabular}{|l|}
$70-79$ \\
years
\end{tabular} & \begin{tabular}{|l|}
$80-89$ \\
years
\end{tabular} & $\begin{array}{l}60-69 \\
\text { years }\end{array}$ & \begin{tabular}{|l}
$70-79$ \\
years
\end{tabular} & \begin{tabular}{|l|}
$80-89$ \\
years
\end{tabular} \\
\hline & 3 & $\begin{array}{l}1 \\
3\end{array}$ & 1 & & & \\
\hline 0 & 15 & 6 & 3 & & & \\
\hline 0.42 & 22 & 21 & 6 & 5 & 2 & 1 \\
\hline 0.44 & 20 & 27 & 12 & 5 & 4 & 1 \\
\hline 0.4 & 11 & 28 & 7 & 15 & 7 & 2 \\
\hline 0.4 & 6 & 9 & 10 & 14 & 16 & 4 \\
\hline 0.50 & - & 8 & 3 & 23 & 18 & 5 \\
\hline 0.52 & 3 & 3 & 3 & 9 & 12 & 6 \\
\hline 0.54 & - & & 1 & 4 & 8 & 10 \\
\hline 0.56 & - & 2 & - & 3 & 1 & 5 \\
\hline 0.58 & - & - & - & - & 2 & 4 \\
\hline 0.60 & - & - & - & - & 2 & \\
\hline 0.62 & - & - & - & - & 1 & \\
\hline 0.6 & - & - & - & - & - & 1 \\
\hline Total & 88 & 108 & 46 & 78 & 73 & 39 \\
\hline
\end{tabular}

TABLE II

Means, Standard Deviations, and Coefficients of Variation of the Heart Lung Coefficient By SeX AND 10-year Age Groups

\begin{tabular}{c|c|c|c|c|c|c}
\hline \multirow{2}{*}{ Age group } & \multicolumn{3}{|c|}{ Men } & \multicolumn{3}{c}{ Women } \\
\cline { 2 - 6 } & Mean & $\begin{array}{c}\text { Standard } \\
\text { deviation }\end{array}$ & $\begin{array}{c}\text { Coefficient } \\
\text { of variation }\end{array}$ & Mean & $\begin{array}{c}\text { Standard } \\
\text { deviation }\end{array}$ & $\begin{array}{c}\text { Coefficient } \\
\text { of variation }\end{array}$ \\
\hline $60-69$ & 0.44 & 0.034 & 7.75 & 0.50 & 0.033 & 6.69 \\
$70-79$ & 0.46 & 0.035 & 7.54 & 0.51 & 0.039 & 7.70 \\
$80-89$ & 0.47 & 0.035 & 7.55 & 0.54 & 0.043 & 8.02 \\
\hline
\end{tabular}

All the subjects in this series were healthy and thus the entire ranges of the heart lung coefficient may be regarded as normal. It is of value, however, to possess upper and lower limits beyond which the occurrence of normal recordings are relatively infrequent. Opinions of what may be regarded as such limits vary from one observer to the next, but the 10th and the 90th percentiles are convenient limits. On this criterion the central 80 per cent ranges of the distributions are certainly normal, while observations occurring outside these ranges, though also possibly normal, are more suspect, particularly those within the upper and lower 2.5 per cent extremes of the distributions. Cumulative percentage frequencies were calculated from the frequency distributions shown in Table I, and the cumulative percentage curves drawn from these data are shown in Fig. 1 and 2 for men and women respectively. In addition, the 10th, 50th (median) and 90th percentiles are shown for each age group. From these curves are obtained directly the selected percentile values for the heart lung coefficient which are shown in Table III. Thus the lower and upper limits, as represented by the 10th and 90th percentiles, for the age groups 60-69, 70-79, and 80-89 are for men 0.40 and $0.48,0.42$ and 0.50 , and 0.42 and 0.52 respectively. The corresponding figures for the women are 0.45 and $0.53,0.46$ and 0.56 , and 0.48 and 0.58 .

The reasons that account for the increase in the heart lung coefficient with age are complex, require further investigation, and are beyond the immediate scope of this paper. Nevertheless, the coefficients of correlation of the variables to age are of interest (Table IV). There is a significant 
MALE

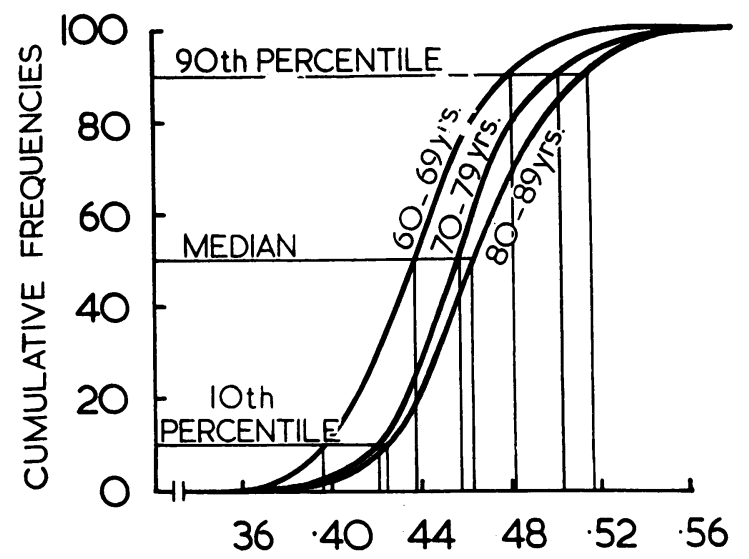

HEART LUNG COEFFICIENT

Fig. 1.-Cumulative frequency curves by ten-year age groups of the heart lung coefficient for men.
FEMALE

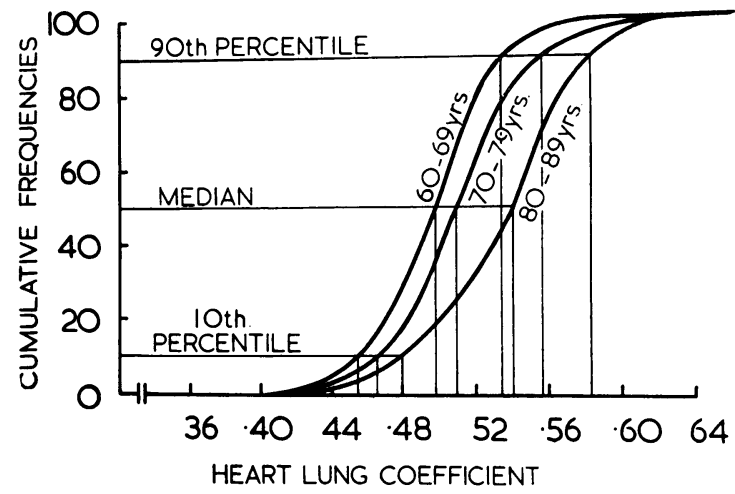

Fig. 2.-Cumulative frequency curves by ten-year age groups of the heart lung coefficient for women.

TABLE III

Selected Percentile Values for the Heart lung Coefficient Derived from the Cumulative Percentage Curves shown in Fig. 1 and 2, by SeX and 10-year Age Groups

\begin{tabular}{|c|c|c|c|c|c|c|}
\hline \multirow[t]{2}{*}{ Percentiles } & \multicolumn{3}{|c|}{ Men } & \multicolumn{3}{|c|}{ Women } \\
\hline & $\begin{array}{l}60-69 \\
\text { years }\end{array}$ & $\begin{array}{l}70-79 \\
\text { years }\end{array}$ & $\begin{array}{l}80-89 \\
\text { years }\end{array}$ & $\begin{array}{l}60-69 \\
\text { years }\end{array}$ & $\begin{array}{l}70-79 \\
\text { years }\end{array}$ & $\begin{array}{l}80-89 \\
\text { years }\end{array}$ \\
\hline $\begin{array}{l}90 \\
75 \\
50 \\
25 \\
10\end{array}$ & $\begin{array}{l}0.48 \\
0.46 \\
0.44 \\
0.41 \\
0.40\end{array}$ & $\begin{array}{l}0.50 \\
0.47 \\
0.46 \\
0.44 \\
0.42\end{array}$ & $\begin{array}{l}0.52 \\
0.49 \\
0.47 \\
0.44 \\
0.42\end{array}$ & $\begin{array}{l}0.53 \\
0.52 \\
0.50 \\
0.47 \\
0.45\end{array}$ & $\begin{array}{l}0.56 \\
0.53 \\
0.51 \\
0.49 \\
0.46\end{array}$ & $\begin{array}{l}0.58 \\
0.56 \\
0.54 \\
0.51 \\
0.48\end{array}$ \\
\hline
\end{tabular}

TABLE IV

COEFFICIENTS OF CORRELATION

\begin{tabular}{|c|c|c|c|}
\hline $\begin{array}{l}\text { Age-Maximum transverse diameter of heart } \\
\text { Age-Maximum transverse diameter of chest } \\
\text { Age-Heart lung coefficient }\end{array}$ & $\begin{array}{l}\cdots \\
\cdots \\
\cdots\end{array}$ & $\begin{array}{c}\text { Men } \\
0.2691 \pm 0.064 \\
0.0305 \pm 0.064 \\
0.3389 \pm 0.064\end{array}$ & $\begin{array}{c}\text { Women } \\
0.0299 \pm 0.07 \\
-0.3424 \pm 0.07 \\
0.3769 \pm 0.07\end{array}$ \\
\hline
\end{tabular}

positive correlation between age and the transverse diameter of the heart for men, but not for women. There is a significant negative correlation between age and the transverse diameter of the chest for women, but not for men. There is a significant positive correlation between age and the heart lung coefficient for both sexes.

\section{Discussion}

Opinions differ concerning the value of the heart lung coefficient. Kerley (1950) regards the heart lung coefficient as a fairly reliable guide to the size of the heart, since the shape of the heart is to a large extent dependent on the shape of the chest. White (1945), however, states that the heart 
lung coefficient is unreliable and unsatisfactory because of the extremely wide range of the normal, while Ungerleider and Gubner (1942) consider that it is crude and inexact, as the width of the chest is only a rough index of body stature and that it is altered in any given case by respiration. The concept of Kerley (1950) seems the most reasonable for more reasons than the one that he records. The coefficient of variation is a measure of the relative variability or scatter of frequency distributions, and the approximate coefficient of variation of 7.7 for the heart lung coefficient indicates that, far from showing a wide range of normality, it has a most moderate variability. Indeed the coefficients of variation for man, that are listed by Pearl (1930), show that the characteristics with coefficients of variation less than 7.7 are largely skeletal. Examples of coefficients of variation greater than 7.7 are the intelligence quotient, 18.01 ; vital capacity, 17.90; respiration rate per minute, 17.80 ; and body weight, $10 \cdot 37$. In addition, the coefficient of variation of the systolic blood pressure of the patients in this series is about 13.0. Considering the assessment of systolic blood pressure no one would suggest that it be discarded, because the scatter of its frequency distribution is almost twice that of the heart lung coefficient and its method of recording is notoriously variable. The fact that the maximum transverse diameter of the chest may be only a rough index of body stature does not necessarily imply that the heart lung coefficient is crude and inexact. Much more important is the realization that any range of normality which relates to the cardiovascular system must take cognizance of adiposity. It is known that adiposity exerts a significant influence on the cardiovascular system and, therefore, adiposity must be regarded fundamentally as a pathological entity to which normal limits do not apply. The adverse influence of respiration on the heart lung coefficient must be diminished in old age, because there is a significant negative correlation between age and chest expansion (Cowan 1956). Thus it is apparent that the heart lung coefficient, used judiciously and in conjunction with systolic and diastolic blood pressure values, can be of help in the evaluation of border-line cases in the older age groups, where the cardiovascular system is suspect.

Danzer (1919), without stating the age or sex of his cases, recorded a range for the cardiothoracic ratio of 39 to 50 per cent with an average value of 45 per cent. This is similar to the ranges noted in this paper for men, but is much less than the ranges for women. He stated that anything over 52 per cent was certainly pathological. This statement is not necessarily true for older men and is completely misleading in the case of older women for whom the 90 th percentile levels for the age groups $60-69,70-79$, and $80-89$ are $0.53,0.56$, and 0.58 respectively.

Tirman and Hamilton (1952) in a study of men aged 20 to 75 years, with only 11 of the men over the age of 60 years, found no real increase in the average values for the maximum transverse diameter of heart or chest, but suggested that the increase in the size of the heart may be an ageing feature, which is late in appearing to a significant extent. In this series, which deals more comprehensively with the higher age ranges, the increase in the maximum transverse diameter of the heart with age is significant, while the average values for the chest diameter remain essentially stationary. This, however, only applies to men, while women show a significant negative correlation between the maximum transverse diameter of the chest and age, with no correlation of any significance between the maximum transverse diameter of the heart and age. Thus the significant positive correlation between the heart lung coefficient and age for both sexes is apparently due to different causes. It is difficult to believe that the significant change in chest width with age in women is due to a selective mortality involving those with the broadest chests, and it is more probable that the reason lies in the possibility that women are subject to greater degrees of kyphosis than men with a corresponding decrease in the maximum transverse diameter of the chest. Further investigation is necessary to clarify this problem.

\section{SUMMARY}

The value of the heart lung coefficient in clinical medicine has been assessed with reference to 242 men and 190 women, aged 60 to 89 years, who were in good health.

The 10th and 90th percentile limits of the heart lung coefficient for the age groups $60-69,70-79$, 
and 80-89 are for men 0.40 and $0.48,0.42$ and 0.50 , and 0.42 and 0.52 respectively. The corresponding values for women are 0.45 and $0.53,0.46$ and 0.56 , and 0.48 and 0.58 . The application of the ratio of $1: 2$ to older women as a level of normality will give misleading information concerning the existence of cardiac enlargement.

Both sexes show a significant positive correlation between the heart lung coefficient and age. In men this is due to an increase in the maximum transverse diameter of the heart with age, while in women it is the result of a significant negative correlation between the maximum transverse diameter of the chest and age. Further investigation is necessary to explain the increase in the heart lung coefficient with age in women.

\section{REFERENCES}

Anderson, A. B. (1948). The Practice of Endocrinology, p. 319. Eyre \& Spottiswoode, London. Anderson, W. F., and Cowan, N. R. (1955). Lancet, 2, 239. Cowan, N. R. (1956). Health Bulletin, Department of Health for Scotland, 14, 50.

Danzer, C. S. (1919). Amer. J. med. Sci., 157, 513.

Kerley, P. (1950). A Text-Book of X-ray Diagnosis, p. 19. Lewis, London.

Levine, S. A., and Harvey, W. P. (1949). Clinical Auscultation of the Heart, p. 145. Saunders, Philadelphia.

Pearl, R. (1930). Medical Biometry and Statistics, p. 347. Saunders, Philadelphia.

Tirman, W. S., and Hamilton, J. B. (1952). Amer. J. Gerontology, 7, 384.

Ungerleider, H. E., and Gubner, R. (1942). Amer. Heart J., 24, 494.

White, P. D. (1945). Heart Disease, p. 127. Macmillan, New York. 